\title{
Desenvolvimento de um Irradiador Portátil para Calibração de Detectores de Partículas Carregadas
}

\author{
Mônica C. de Mello (IC), Gustavo A. Lombardi (IC), Sandro Guedes (PQ).
}

\begin{abstract}
Resumo
A fim de construir um irradiador portátil para calibração de filmes finos de Boro para a dosimetria do BNCT, foram realizados testes com detectores PADC irradiados com um filme fino de Am-241 a 1 mbar. Encontrouse a atividade de $19,46 \pm 0,42 \mathrm{kBq}$ e densidade superficial de átomos de Am-241 $(3,05 \pm 0,66) \times 10^{15}$ átomos $/ \mathrm{cm}^{2}$. O sucesso do experimento mostrou que é viável utilizar o método proposto para calibrar fontes que emitem partículas somente em reações nucleares.
\end{abstract}

Palavras-Chave: Bomba sorção, ângulo crítico, detectores plásticos.

\section{Introducão}

A BNCT é uma terapia de câncer que usa a captura de nêutrons pelo Boro-10 para irradiar células tumorais por meio da emissão de uma partícula alfa e do núcleo de recuo (Li-7). Essa terapia minimiza os danos colaterais da radioterapia convencional e aumenta a qualidade de vida do paciente.

Para que a BNCT seja aplicada, é necessário o desenvolvimento de técnicas de radiometria que permitam o cálculo de doses. Para isso, usa-se filmes de Boro acoplados em detectores de partículas carregadas (PADC, polialil-diglicolcarbonato), usados para medir as fluências de nêutrons térmicos e rápidos, durante a irradiação. O objetivo do trabalho é construir um irradiador portátil para a calibração de fontes radioativas depositadas como filmes finos. Nesta etapa, apresentamos um teste da eficácia do método proposto, usando uma fonte de Amerício-241, emissora de partículas alfa, ao invés de irradiar filmes de boro com nêutrons. Este experimento pode ser feito de forma mais controlada, sem termos de lidar com as demandas do reator.

\section{Resultados e Discussão}

Para determinação da atividade da fonte radioativa de Amerício-241, foram realizadas irradiações de detectores do tipo CR-39 no vácuo (1mbar) utilizando uma bomba mecânica EDWARDS modelo E2M30 do Laboratório de Metais e Ligas em diferentes intervalos de tempo. Depois das irradiações, os detectores foram para - Laboratório de Cronologia e passaram por processo de ataque químico em solução de $\mathrm{NaOH}$ com concentração 6.25M à temperatura de $70^{\circ} \mathrm{C}$ por 400 minutos. Posteriormente, os traços presentes nos detectores foram contados em um microscópio óptico no aumento de 500 vezes.

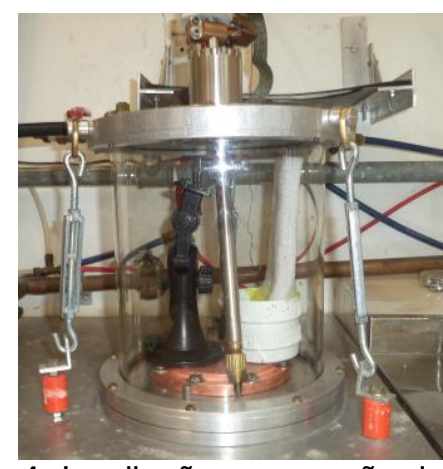

Figura 1. Irradiação na pressão de $1 \mathrm{mbar}$

Analisando os dados desse experimento, o qual foi realizado no período anterior de vigência da bolsa, foi determinada a atividade inicial da fonte de Amerício-241 utilizada (19,46 \pm 0,42 kBq). Também foi encontrado um valor para a densidade superficial de átomos de Am-241 da fonte de $(3,05 \pm 0,66) \times 10^{15}$ átomos $/ \mathrm{cm}^{2}$. A principal fonte de erro provém da radiação residual resultante do tempo necessário para a câmara de vácuo atingir a pressão desejada e retornar à pressão ambiente.

\section{Conclusões}

O experimento realizado demonstrou que é possível fazer a calibração de fontes radioativas pelo método proposto. Assim, construir um irradiador portátil com um sistema de vácuo permite que sejam realizadas calibrações da fonte radioativa e do detector em outros laboratórios e mesmo durante irradiações com nêutrons. Esta característica é especialmente útil para os casos em que as partículas são provenientes de reações nucleares. Este é o caso dos filmes finos de Boro necessários para a dosimetria do BNCT.

Agradecimentos

Agência financiadora: $\mathrm{PIBIC/CNPq}$ Laboratório de Metais e Ligas/DEQ/UNICAMP. 